University of Wollongong

Research Online

Faculty of Engineering and Information

Faculty of Engineering and Information

Sciences - Papers: Part A

Sciences

$1-1-2010$

The diffusion of RFID implants for access control and epayments: a case study on Baja Beach Club in Barcelona

Katina Michael

University of Wollongong, katina@uow.edu.au

M G. Michael

University of Wollongong, mgm@uow.edu.au

Follow this and additional works at: https://ro.uow.edu.au/eispapers

Research Online is the open access institutional repository for the University of Wollongong. For further information contact the UOW Library: research-pubs@uow.edu.au 


\title{
The diffusion of RFID implants for access control and epayments: a case study on Baja Beach Club in Barcelona
}

\author{
Abstract \\ RFID implants for humans have been used in a variety of contexts since their commercial inception in \\ 2003. The VeriChip product which typically carries a 16 digit number was first marketed as an \\ identification device in the ehealth space (e.g. for emergency response), then as an access control \\ mechanism (e.g. security), and finally as an epayment solution (e.g. the purchase of drinks at clubs). This \\ paper investigates the story behind RFID implants for club patronage access control and epayment. The \\ study uses a two-fold qualitative approach in the collection of data for the single case study of the Baja \\ Beach Club in Barcelona, Spain. A single semi-structured interview was conducted with the IT Manager \\ who created the application at the club that utilised the human chipping product. The full length interview \\ was conducted in Spanish, translated into English, and analysed using content analysis. The interview \\ was supported by an exhaustive search online for documents that met the criteria "Baja Beach Club + \\ implants". The documents returned by this search included academic articles, government policy \\ documents, publicly accessible blogs and media commentary. Search engine results online uncovered \\ one other dominant document type- that of popular religious literature linking implantable microchips in \\ humans to end-time prophecy in the Book of Revelation, the last book of the New Testament. The findings \\ indicate that despite the successful application of RFID implants for club patrons, the complexity of the \\ technology during trialability led to its stilted diffusion. The paper draws on Roger's (1995) diffusion of \\ innovation (DOI) theory to describe the poor uptake of the technology for access control worldwide but \\ points to the possibility that this is only a short-term trend. The paper also ponders on whether the slow \\ rate of adoption of humancentric implantables will continue and what factors might need to be overcome \\ before widespread diffusion can occur.
}

\section{Keywords}

baja, beach, club, barcelona, diffusion, rfid, implants, access, control, epayments, case, study

\section{Publication Details}

Michael, K. \& Michael, M. G. (2010). The diffusion of RFID implants for access control and epayments: a case study on Baja Beach Club in Barcelona. In K. Michael (Eds.), IEEE Symposium on Technology and Society (pp. 242-252). Singapore: IEEE. 


\title{
The Diffusion of RFID Implants for Access Control and ePayments: A Case Study on Baja Beach Club in Barcelona
}

\author{
Katina Michael, M.G. Michael \\ School of Information Systems and Technology, University of Wollongong \\ \{katina,mgm\}@uow.edu.au
}

\begin{abstract}
RFID implants for humans have been used in a variety of contexts since their commercial inception in 2003. The VeriChip product which typically carries a 16 digit number was first marketed as an identification device in the ehealth space (e.g. for emergency response), then as an access control mechanism (e.g. security), and finally as an epayment solution (e.g. the purchase of drinks at clubs). This paper investigates the story behind RFID implants for club patronage access control and epayment. The study uses a two-fold qualitative approach in the collection of data for the single case study of the Baja Beach Club in Barcelona, Spain. A single semi-structured interview was conducted with the IT Manager who created the application at the club that utilised the human chipping product. The full length interview was conducted in Spanish, translated into English, and analysed using content analysis. The interview was supported by an exhaustive search online for documents that met the criteria "Baja Beach Club + implants". The documents returned by this search included academic articles, government policy documents, publicly accessible blogs and media commentary. Search engine results online uncovered one other dominant document type- that of popular religious literature linking implantable microchips in humans to end-time prophecy in the Book of Revelation, the last book of the New Testament. The findings indicate that despite the successful application of RFID implants for club patrons, the complexity of the technology during trialability led to its stilted diffusion. The paper draws on Roger's (1995) diffusion of innovation (DOI) theory to describe the poor uptake of the technology for access control worldwide but points to the possibility that this is only a short-term trend. The paper also ponders on whether the slow rate of adoption of humancentric implantables will continue and what factors might need to be overcome before widespread diffusion can occur.
\end{abstract}

\section{Introduction}

On the 12th of May 2004, news broke in the United States of a club in Barcelona that was implanting patrons under the skin with 'electronic credit cards' [1]. Put simply, an RFID transponder was being inserted into the body of a consenting club patron, a unique code identifying the individual, which could then be used for electronic payment and as an access control mechanism to special VIP (very important 'patron') only areas. The Baja Beach Club in Barcelona, Spain [2] was one of two clubs (both carrying the same name) to conduct the RFID implant trial. The other was the Baja Beach Club located in Rotterdam, The Netherlands [3], although there was allegedly a third Baja location implanting patrons in the United States. The Baja Beach Club was founded in 1985 by Mr. Larry S. Spatz [4]. He and two other partners developed Baja into the largest nightclub chain in the United States and later expanded into Europe, with operations in the United Kingdom, Spain, and Holland, making it at one time the largest night club chain in the world.

The organisation involved in developing the implantable chip for humans was the Verichip Corporation [5] (known as 'CHIP' on the NASDAQ), once a subsidiary of Applied Digital Solutions (now known as the Digital Angel Corporation) [6]. Marketing plans for the VeriChip began in October of 2002, just over a year after September 11, 2001 terrorist attacks [7]. One of the earliest patent applications in the area of implantables for living creatures was filed by Mejia and Casey on the passive integrated transponder (PIT) tag comprising of an integrated circuit and a unitary core (patent: 20020154065) [8]. VeriChip received clearance from the Food and Drug Administration (FDA) to distribute its RFID transponder as a medical device in October of 2004 [9]. A reclassification request to a device of type class II was made by the owner of the VeriChip product so there could be a reasonable assurance of safety and effectiveness of the device [10]. A single adverse event report was submitted to the FDA on the 27 July 2007 pertaining to the removal of the chip after the bearer experienced discomfort at the point of implantation some 
hours after the initial insertion [11]. While the U.S. Food and Drug Administration provided permission for the VeriChip to be fit for use as a device for electronic health monitoring, little is known about the commensurate jurisdictional authorisation gained in the European Union and South America at the time the product was rolled out for club patronage and security access control, respectively.

\section{Conceptual Framework}

Of all the scenarios [12] that were developed for the implantable microchip, the following applications reached either a proof of concept or were actually tested in the marketplace: identification, emergency response, electronic health record (HER) identifiers, club patronage, VIP access, epayment, security access, physical perimeter access, prison inmate tracking and monitoring, employee access control, location services, asset tracking (including object-to-subject tracking, and subject-to-subject tracking), Alzheimer's wandering, the collection of physiological parameters remotely, glucose and other biodrug delivery devices, virus detection etc. What is interesting to ponder is why it was a part of an international club chain that was chosen as one of the first markets to trial the complex technology. The diffusion of innovation (DOI) theory [13] can help to frame such discourse and will be used here to study the potential adoption of a complex product, the implantable microchip for humans.

\subsection{The Commercialisation of Complex Products}

Studies in innovation will always emphasise that a technology itself is not a product; that only when a technology is linked and implemented for a given application or context does it become a fully-fledged product. This is especially true of high-technologies which are considered complex as they often bear dual capabilities as a product and a process. The implantable microchip is one such complex technology that relies on a system of component devices and processes to function. But beyond the complexity in the actual implantable "system", in terms of commercialisation neither the technology nor the markets were well-defined or understood.

In the case of the RFID transponder implant for humans, the technology has evolved since its original inception for animal identification, and the potential markets are presently evolving with it over time. There is to some degree a process of co-evolution occurring as developers and users interact [14]. Developers in the case of the implantable device must not be constrained to meaning the product developers alone but must include a number of stakeholders in the value chain, such as the manufacturers, application developers, network access providers, third party equipment providers, ehealth professionals (i.e. conducting the implantation), government agencies etc. And users are not merely people, but can include organisations that provide endusers with the opportunity to receive an implantable chip for a given application, and these can be merchants (e.g. potential issuers) or organisations where end-users hold a private interest (e.g. clubs).

In investigating the potential adoption of microchip implants for humans, forecasting on the basis of functionality or performance would have been futile. Even doing a technical comparison between alternative technologies, such as weighing up epayment solutions against several techniques like magnetic-stripe card, smart card and biometric payment solutions would not provide any foolproof evidence for predictive analysis. We have long known of the insecurities of magnetic-stripe cards for credit card payments, and yet the adoption of smart cards has been relatively slow in markets like the United States and Australia. Simply because the performance of smart cards is known to outstrip magnetic-stripe cards for credit card payments, it has not meant an immediate shift in market share of card technology types worldwide. There are therefore two parts to the puzzle- the first is certainly to look at the pros and cons of adopting one technology over another alternate technology, but then to consider how target customers might react in a behavioural sense.

In the case of the trial of microchip implants for Baja Beach club patrons in Spain and The Netherlands, what we have witnessed is the implantation of only one of numerous application types (a specific technical segmentation) against a single customer type (club patrons fitting a certain demographic) tested over several jurisdictions. In the case of the Baja Beach Club in Barcelona, Spain, not more than 100 people were implanted for VIP access and epayment, thus the technical segmentation was conducted on a very small group of users. The need to analyse the same product in several jurisdictions was to identify the similarities and differences in the user requirements. Comparing the behaviours of club patrons in Spain and The Netherlands (i.e. both European Union member states and typically consisting of patrons of the same demographic) meant that behaviours in adoption could be analysed between markets. Thus, by combining technical segmentation by application with behavioural segmentation by critical success factors, a big picture view begins to emerge about the likelihood of commercialising the implantable microchip.

An outcome of the microchipping of club patrons proved to reaffirm what is widely reported in the innovation literature; that risk is central to the buying 
process for complex products. This is especially true of automatic identification and location-based services which can be considered as both a product and process [15]. Consider what happened in the case of Baja Beach Club in Spain. A patron visiting the club was provided with the opportunity to have an implant to access VIP areas and conduct electronic payments. To actually buy-in to the implantable product each individual would have to evaluate the risks. Risk can be defined as "a function of a buyer's level of uncertainty and the seriousness of the consequences of the decision to purchase" [14]. For a product that can be considered completely new besides its use-case in animals or nonliving things, it can be assumed that the perceived risks as they pertained to end-users were deemed prohibitively high.

The main points surrounding the perceived risks of patrons were almost certainly associated with implanting high technology beneath the skin, the ability to be tracked and monitored or have confidential information lost, potential health exposures of implanting an integrated circuit, the reliability and performance factors, the ease of removing the device in the future, and personal philosophical, cultural or religious clashes with the symbolism imbued by an implantable for anything other than prosthetic requirements. Thus we can separate the perceived risks into two main categories- those pertaining to performance risk, and those pertaining to psychological risks. In the case of the VeriChip product application trials, both performance and psychological risks were found to be present.

\subsection{Characteristics Affecting the Diffusion of Innovation}

When analysing the characteristics affecting the diffusion of implantable microchips for club patrons, one needs to question the original motive behind the roll-out of the technology. Was it a market research study [16], was it a trial of a prototype, or was it adoption at the "innovators" stage of the diffusion process? One might also play the devil's advocate and ponder that it had nothing to do with any of these motivations, but rather gaining mind-share in the general public regarding the feasibility of future services based on implantable devices for health and non-health initiatives. The media had a great role to play in popularising implantable microchips, a great story bordering on the science fiction, only this time it was reality. A story being sold on the grounds that it was now a real possibility for future generations, at least, to do away with plastic cards towards a real cashless society.

Rogers' [13] five perceived attributes of innovations provide a vehicle for discussion with respect to implantables for humans, and their current rate of adoption. Relative advantage, compatibility, complexity, trialability and observability are the five aspects of implantable technology for humans that will be explored in the main body of this paper. These attributes should act to shed light on why the uptake of implantable solutions has been so low for access control applications. The paper will also ponder on whether the slow rate of adoption will continue and what factors might need to be overcome before widespread diffusion can occur.

\section{Methodology}

The methodology used to explore the commercialisation of RFID implants for access control was that of a single case study. Exploratory research in innovation is about understanding the background context, and to crystallize problems associated with new technologies, and their prospective impact and benefit to society [17]. One of the primary aims of conducting exploratory research pertains to diagnosing a situation, beyond discovering new ideas. The case study method investigates a single situation intensively. It does not seek to generalise but to observe phenomena which might shed light on the current situation and may be used as a trigger for further research.

\subsection{Case Study Method}

A single case study will be presented in this paper of the Baja Beach Club located in Passeig Maritimo de la Barceloneta, Barcelona, Spain. The case will focus on the implementation of microchip implants for patrons of a single Club, despite that there were several other clubs in the chain that also deployed similar RFID-implant systems. The Baja Beach Club in Barcelona, was that club which received by far the greatest amount of attention by the western media, between 2004 and 2008. It should be noted that the premises is now under new management and the implant scheme has been discontinued.

The data collected for the case study was provided by a single semi-structured interview and exhaustive online document collection. The data was analysed using content analysis software and presented in a narrative form. Rogers' five perceived attributes of innovation were used to frame the findings of the study.

\subsection{Semi-structured Interview}

The semi-structured interview was conducted with the former employee of Baja Beach Club who was responsible for the actual implementation of the RFID implant system at the Barcelona club. The interviewee had the role of Information Technology Manager, was a 
Spanish citizen, a male aged 31 years of age at the time of the interview, and who did not possess tertiary level qualifications. The young male was a self-taught web designer, clearly talented and self-assured of his skills, and had other business interests besides working at the Club. The semi-structured interview took place in Barcelona City, on the 4th of June, 2009, and took 45 minutes to complete during the interviewees lunch hour. A translator was present, as the interviewee had only a working knowledge of English. The interview mainly focused on gathering facts about the Baja Beach Club establishment [18]. Furthermore, the interview aimed at learning about people's beliefs and perspectives relating to the voluntary implantation of patrons at Baja Beach Club and the specifics of the creation, design, implementation, operation and maintenance of the RFIDbased system. There were also questions pertaining to feelings and motivations behind the roll-out of the application, and management perceptions of the advantages and disadvantages, risks and benefits of the system to patrons and Club owners. The broad themes addressed can be seen in Figure 1. The interview was transcribed and translated by a final year American undergraduate information technology student who held a minor in Spanish from Indiana University.

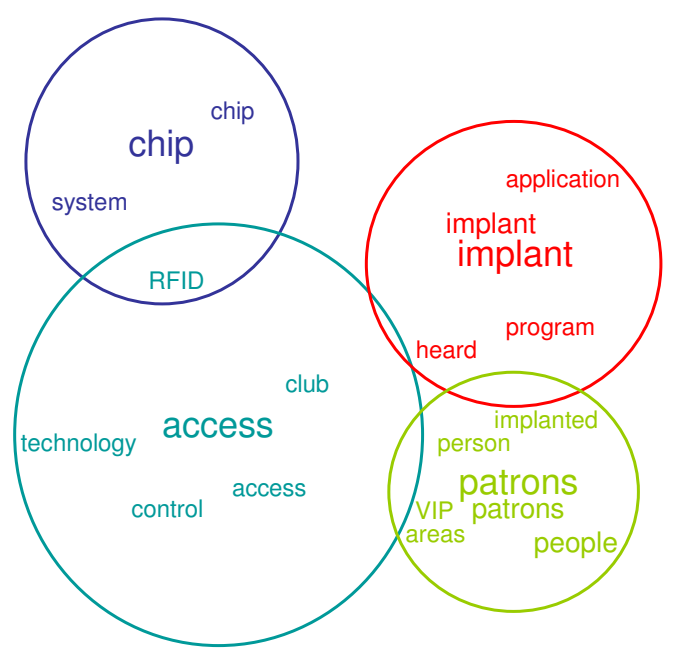

Figure 1. Themes addressed in the interview with the former IT Manager of the Baja Beach Club in 2009

\subsection{Documentary Online Secondary Data}

The online documentation search was conducted using an iterative process [19]. The main search used to gather the greatest number of relevant documents was "Baja Beach Club + implants" which returned over 7,000 individual results using the Google Search Engine. Of these total documents, only $2 \%$ were considered to fall into the following categories: academic or conference paper or presentation, industry/trade news or magazine, government policy and position papers, traditional online news media. In the second stage of the online search process, documents pertaining to a social, religious, philosophical or cultural basis were drawn from the results, yielding a significant portion of hit results. It must be emphasised that there was a great deal of duplication of online documentation, cross-posted to blogs for instance. Duplicates were removed and not included in the content analysis so that bias was not introduced in the sample size. The results of the documentation pertaining to the social context within which RFID implants are perceived is in no way meant to be representative of the consensus on the applicability of such systems for non-medical purposes. However, we can point to the issues raised by authors of such materials, as being important, albeit to one or more sub-groups.

\section{The Case of Baja Beach Club in Spain}

\subsection{Chipping Club Patrons}

The Baja Beach Club implementation of the radiofrequency identification (RFID) transponder acted to allow club patrons to pay for items purchased with a 'swipe' of their hand (epayment solution), and also to allow implantees to access Very Important Persons (VIP) zones within the club. The implant service for patrons was launched in August 2004 with only 12 persons adopting the solution by year-end [20], and implantation occurring on Tuesday evenings. Although widely cited in the secondary online data that becoming a VIP patron by being implanted cost about 100 euro dollars, the IT manager stated in the interview that participants in the service were not charged to be implanted, given they would often spend a great deal of money at the Club anyway and so charging extra for implantation hardly made sense.

The decision to deploy RFID transponder implants to patrons came from the young manager of the Club, $\mathrm{Mr}$ Conrad Chase, who had previously visited the United States and heard about the use-case of implants in the medical field, especially for the elderly and sick (mainly for identification purposes). He considered the possibility of implanting club patrons in Spain and believed the idea would be of commercial value, even if all it did was to generate discussion via word-of-mouth between patrons and tourists to the area, thus creating an aura around the brand, and acting to generate revenue by drawing large crowds. The implants were also used by staff at the Club 
to provide access control to various sections of the Club, thus ensuring additional security and the ability to do away with keys. A picture of the refurbished establishment can be found in Figures 2-3.
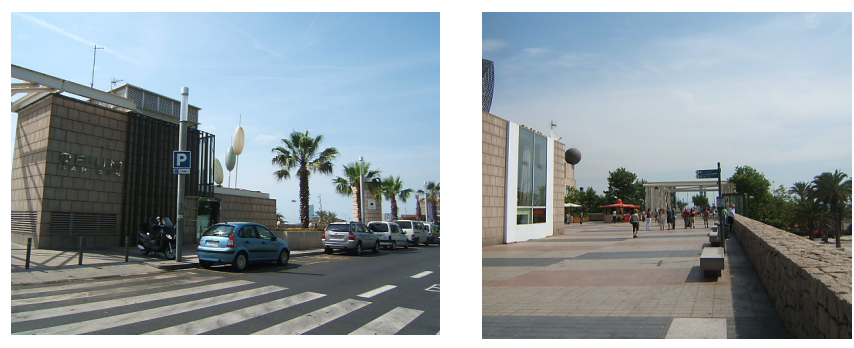

Figure 2. Front/rear street-level access to Baja Beach Club
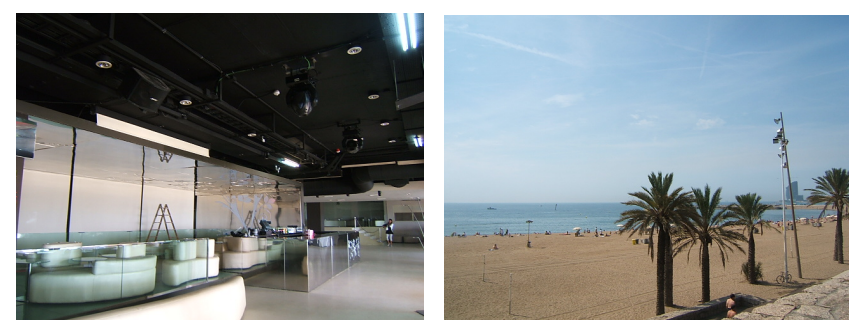

Figure 3. Interior and beach-level access to Baja Beach Club

\section{Results}

\subsection{Relative Advantage}

According to Rogers, "[r]elative advantage is the degree to which an innovation is perceived as being better than the idea it supersedes" [13]. Certainly for the product and application developers of the human implantable microchip, the technology superseded credit cards and other paper-based or biometric-based access control mechanisms to VIP zones. In terms of relative advantage with respect to economic terms, it was perceived by management initially that there would be a saving in time and effort to grant access to VIP patrons in particular zones. It was also noted that the ease of using the device to pay for purchases at the Club was so effortless, that it might indeed act to an increase in sales as no physical cash in the form of notes or coins was actually being exchanged. However, this also meant that by offering an implant-only epayment solution that the solution had to be as ubiquitous as normal credit or electronic funds transfer at point of sale (EFTPOS) facilities on the premises. So initial start up costs, besides the existing cash register were a reader to read the RFID implant, and a computer that could run the epayment application at each point of sale (POS), along with specialist training to staff to use the equipment.

Speaking in terms of relative advantage with respect to non-economic factors, e.g. social factors, the implant solution was supposed to offer implantee patrons an unrivalled convenience when compared to any other club in Barcelona. The convenience would come from not having the requirement to carry cash or credit on oneself or a physical purse. It also meant that clothing worn to the club did not need to have pockets. This was perceived to be of greater benefit to females whose apparel generally is not fitted with secure deep pockets for aesthetic reasons. It also meant that patrons enjoying the summertime on the beach till late, could walk into the club without having to worry about bags being stolen or otherwise. It is not uncommon to find club patrons today who have attached valuable items such as passports or driver's license and credit cards in secret pockets in the inner lining of garments or in a sentinel jacket that is connected to the person via a necklace.

The social prestige of being an implantee was obvious when the IT manager noted: "[o]ur implanted patrons would have access to special VIP areas, and when they walked into the club, their name would automatically flash up on a big screen and a loud beep could be heard echoing throughout the club... the reaction by the other clubbers was always 'Oh, look, so and so is here and he is bearing an implant in his body', or 'Ah, here comes that person again, he is special'. It was quite interesting to sit back and watch peoples' reactions... it was at times quite amusing really... but the implantee patrons, really loved the extra attention, and people would instantly go up to them and talk to them and strike a conversation about anything... they were no longer anonymous, but were very approachable because people knew their name." Obvious from this excerpt is that there was a fair bit of the "cool factor' involved in this type of prestige. The IT Manager believed it brought these VIP patrons 'instant' reward, in terms of prestige. He noted: "[ $\mathrm{t}]$ hey were different and there was an attraction in that... our VIP patrons were pretty big spenders, they had a sizeable budget... so if your name flashed up on the screen, pretty much, people knew you were quite wealthy."

But it should be noted that relative advantage indicates not only the benefits but the costs resulting from the adoption of an innovation. While the humancentric RFID application did not take long to design, implement, test and operate, i.e., not more than three months in total, the costs of operating a dual epayment solution was not insignificant, when one considered that it took several persons with different skill-sets to register and enroll an 
individual patron onto the RFID-based system. About the only limitation that the IT manager noted of the club patron implant identification system "was that the enrolment process was very messy and required all these people to come together so that just one patron could be registered. It was ... very disruptive to add a new patron to the program. You needed a doctor or nurse, you needed a Club employee who had been trained in the process of registration (and most of the time it was me needing to be available to do the data entry and make sure it was all working as it should be), you needed the patron to make sure they wanted to participate in the trial, and that some kind of light anesthetic would be applied so the person would not feel any pain... It is just not viable as a business process, as there are too many costs involved." Generally, the greater the perceived advantage of using the innovation, the faster the rate of its adoption [21].

\subsection{Compatability}

When a company launches a new product it does so with the knowledge that in some markets it will be more compatible than others; that is, ultimately there will be a higher penetration of a given innovation in some markets before others. Compatability is about the degree to which an innovation is perceived to match the existing values, past experiences, and needs of potential adopters [13]. In the case of microchip implants for humans for access control, the perception is of a less compatible and more uncertain innovation. And perhaps here is the reason, why several different market locations were strategically tested in Europe using implantable microchips. The uptake of the implantable solution at the Baja Beach Club in Spain suggests that the product was incompatible with the sociocultural values and beliefs of the Spanish consumers (figure 4).

While "[y]oung people love new technology" as echoed by the IT Manager, the whole implantable product for humans seems to have ignored a simple rule in the rate of adoption of a new innovation, that if the technology is not compatible with sociocultural value and beliefs it will almost certainly fail. In the case of the microchip implant, a plethora of online secondary data resources indicate a belief that the implant is somehow linked to the fulfillment of prophecy in the Book of Revelation. Figure 4 shows the "beast" concept which is highlighted with direct allusion to chapter 13 verses 16-18 where the charagma is described, a mark on the right hand or forehead. While the authors do not claim for a moment that this type of endtime theology is embraced by all Christian groups, there is a part of the broader community that is opposed to a foreign object being implanted into the body, especially for access control or payment of any kind.
There is a second type of movement that is identified in the secondary online data sources which unlike the stereotyped "religious fundamentalists", often are considered as either conspiracy theorists or engaging with an underground rebellious resistance movement such as anti-government revolts to globalization (e.g. against the G8). There is a complex mesh of voices in this subgroupsome pertain to the upkeeping of human rights, others to the enactment of legislation to guard against enforced chipping of humans, and still others very suspicious of the role the government is playing in surveillance of its citizens. At the heart of the compatability problem is the struggle of people to ensure their information remains private and in countering the power-control issue evident in relations between citizens and their state. If these compatability issues are to subside over time to enable the adoption of RFID implants for humans in a variety of applications (not just club patronage), then it will take "time", it will depend on context, market and "place", and for the public to become more educated on the symbolic and real "meaning" of the "identification number". For now at least, the fine print is missing and the details are absent on how the technology may become an enabler or disabler. The question the content analysis raises, is indeed, how an implant ID used for a given application, may be misused into the future, and what the implications are for all concerned, especially for long-term tracking and access to services of all kinds.

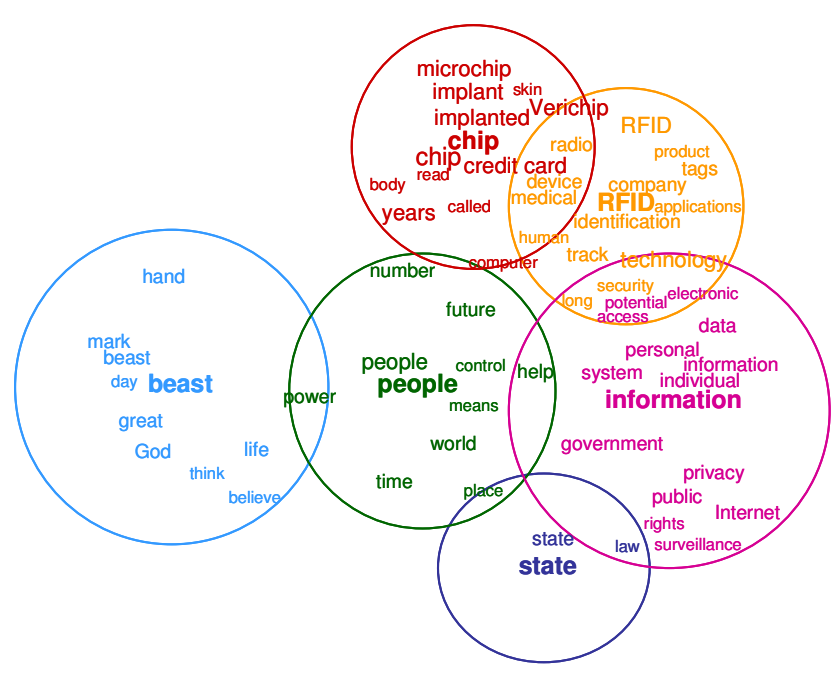

Figure 4 Content Analysis of Internet-blogging about Baja and the RFID implant service directly describing issues pertaining to socialcultural values.

Given that an average uptake of the implantable microchip at Baja Beach Club Spain, amounted to only 22 patrons per annum on average, it is the opinion of the 
authors that the rate of adoption was affected by not only sociocultural values but also a mismatch of product to client needs, and even as a result of a more effective previously introduced club innovation for epayment and access control such as biometrics. It is generally perceived in the literature that compatibility with existing values and norms is of far greater importance than compatibility with existing practices [22]. Existing practices can be changed through a process of mutual adaptation, but values and norms are deeply engrained in the individual psyche and these are often intentionally applied in the decisionmaking process whether they are of a social, religious, cultural or philosophical nature [23].

\subsection{Complexity}

Of all the attributes of innovations, complexity perhaps is the simplest to comprehend. Complexity is the degree to which an innovation is considered to be difficult to understand or use in a relative sense. For example, a technology such as a wooden table can be considered a simple innovation when compared to an embedded beneath-the-skin advanced technology such as radiofrequency identification transponder implants. Figure 4 depicts how every-day people perceive implant systems as complex; and how the Baja Beach Club implementation of the implantable product was perceived by global members of the online community. The main concepts titled, "RFID" and "chip" with the dense number of terms surrounding them, show the perception of the required components by members of the online community with respect to epayment and access control system based on implantable devices. The online community refers to "tags", "technology", "devices", “applications", "products", "security", "electronic", "chips", "computer", "RFID", "radio" and "reads".

Despite the obvious complexity, when asked whether or not the solution at Baja Beach Club required a major integration effort, the reply from the IT Manager was: "[n]ot at all... it was a small customized system that I built. I did not rely on anything more than the RFID device, the readers, the antennas, a database to store the information collected, and the program I built to register patrons on the system and to enable transactions to be processed in real-time." An example of the epayment interface built by the IT Manager is presented in Figure 5 . On the left is a picture showing a computer sitting on a stand near a VIP cordoned off area with a screen shot of the application, and on the right is a captured screen shot conveying how someone purporting to have a Baja Beach club implant was not given access to the VIP zone, as his read attempt was negative and was indicated by the words "NOT OKAY" in the application. Additional complexity was increasingly added to the system as in 2006 Baja
Beach Club recruited a third party organization to assist in the target marketing of club patrons [24].

Despite the IT Manager's elucidations about the simplistic nature of the advanced technology, the matter has more to do with understanding how the system works and what this means for the individual considering implantation. While technologies such as automatic teller machines (ATMs) allow people to understand the generic "process" of withdrawing funds for example, without having the need to know what happens in the back-end systems, implantable solutions are yet another leap into the unknown. Because the component becomes a part of the patron's body, the individual is no longer just "trusting" that the system will work, they most likely want to know more details, in the sense of what it means in the end-to-end process taking place, and what it means for them as a living being. The health domain is somewhat different, as patients requiring a heart pacemaker for instance, often do not have a choice regarding implantation; they just want the pacemaker to work because it means they have a chance at surviving. But when there are choices and options and alternatives, one is a little more skeptical about implanting technologies into a completely healthy body.
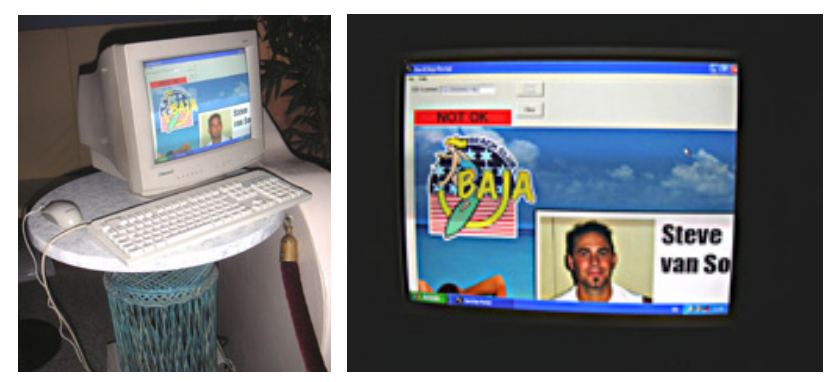

Figure 5 The Complexity of the ePayment Solution. Courtesy of Drew Hemment, Lancaster University

Technical factors usually contribute to an innovation's complexity- such as how is the implant injected, how can it be maintained, and how can it be removed. Indeed when asked whether any of the 100 VIP patron implantees had requested the removal of the implantable microchip, the IT Manager replied: "No, they have not... it is just sitting in their body, it cannot do them any harm." However, what if even one club patron had asked to remove the chip, what then, and how would this be achieved, and at whose expense? Or what if the RFID implantable transponder had been rendered dysfunctional, what then, simply implant the patron with a second transponder into the same location? The absence of standards only acts to increase complexity.

Complexity is present in almost all high technologies on the very basis that a great number of these have the 
dual role of product and process. So whether one talks about actual components of an implantable system such as the one deployed at Baja Beach or the actual processes involved with usage-related technical issues over the longer term, the complexity is ever-present. No matter the kind of advanced technology which is trying to be introduced, if it has anything to do with computing, is wireless, and implantable, and data is stored remotely, then it will come adorned with numerous upfront barriers in any vertical sector or market in which it is deployed.

\subsection{Trialability}

The ever increasing pace of change has had an impact on the number of products that are trialed before commercial diffusion takes place. Trialability is the degree to which an innovation may be tested for a limited duration. This can be a valuable process and time for an innovation, as developers seek to interact with users, and learn from them about their needs, and to identify dysfunctional qualities in the product. The trend in the high-tech space today is toward limited initial deployment, and then for changes to product design to be based on early feedback provided by the first adopters who are often influential leaders in social networks. This is notable, particularly in the luggable and wearable computing space. For users it is a type of learning-bydoing which will hopefully extend to buy-in later. It should be noted also, that trialability may act to reduce the rate of adoption [21], if the line between desirable and undesirable consequences of the innovation cannot be distinguished.

One of the fundamental changes that occurred in implanting patrons at Baja Beach was the physical bodily location where the implant was to reside. At first, the directive by the company supplying the implantable solution was to implant in the upper arm of the individual but this approach was destined to failure based on early patron feedback to do with usability of the system. The IT Manager stated: "...to be honest we realized this [the upper arm] was not the most convenient location and so some people had it implanted on the inside of their wrist. This is the site that gives the individual maximum mobility and is user friendly. We injected so far as the implant could lodge itself in the muscle of the person and would not go moving around inside the body to render the program useless." These are the kind of issues that extensive trials would have shown, but given the solution went straight to market, the issuers of the implant had to respond to patron sentiment 'on the fly'.

It must also be underscored, that "trialability" with particular types of implantable solutions are quite difficult if left in the body for a certain period exceeding 3 months. In actual fact, volunteering to be a part of a trial might mean you are a life-long carrier of an implantable device, even if it is dormant, unless extraction via an operation is possible. When the IT Manager was asked about the fact that the program was now discontinued under new management, and whether the implants in the VIP patrons were just lying their dormant, he responded: "Yes they are dormant and not only that, but they are also quite useless now. Even if someone was to chop off someone's arm to use the ID device, they could not get far with it... I have changed all the ID entry access codes now- it was very simple." It was clear by this remark that the IT Manager was more concerned about the security at the new establishment, then the implications of the dormant device in the human being. This is perhaps somewhat analogous to the gathering of junk in space after many missions, except unlike space, the body is a great deal more limited.

\subsection{Observability}

Observability pertains to how well an innovation is received, or communicated to others. In some cases it is easy to observe an innovation but in other cases it is difficult. In computing the distinction between computer hardware versus software programs can be made. Generally the less observable an innovation is, the slower the rate of adoption. Where the product is less observable, as in the case of microchip implants that are inserted beneath-the-skin, peers who have already inserted an implant can act to propel its uptake by providing "safety credibility" [21]. This was indeed the strategy of the chief executive officer of the VeriChip Corporation, Mr Scott Silverman, who not long after the official approval of the VeriChip by the Food and Drug Administration, pronounced he was bearing a chip. Potential adopters will often seek the advice of those who have lived and breathed the technology to derive the full story about the positive and negative effects of the device.

It was never the intention of the owner of Baja Beach Club Spain to have a high penetration of VIP implantees, as that would simply render the VIP status useless and place too many demands on the organization in terms of employee tasks. Rather, the Club wanted to use the implants as a means to stimulate discussion about the club, and in fact, it was very successful in executing that strategy. Guide books, even popular ones like Lonely Planet, noted the implant application, wrote about it, and encouraged travelers and citizens of Spain, to go and find out first-hand what all the fuss was about. The IT Manager revealed that it "was all about the novelty.... In short, it was a marketing ploy, and it actually worked well. We strongly believed that despite the high-tech application, it was good old traditional word of mouth that would drive people to come and participate in the clubbing experience." 
Observability has a great deal to do with how policy forms around the technique- high visibility is critical for exposure, but it does not always guarantee uptake. In some cases, too much exposure can be counter-productive to the main aim of the issuing party, especially where government policy for instance, has not yet even considered what its stance is on a certain device and respective applications it enables. The deployment of the implantable microchip at the Baja Beach Club in both Spain and The Netherlands in 2004, placed pressure for an Opinion to be released by the European Union in 2005 [25]. The assumption was, that in other markets like Asia, Africa, or North America there would have been too much of a revolt against the technology (e.g. the experience of CASPIAN [26]), while Europe was seen as a larger and also more complex market with a different governance structure, perhaps more easily overcome.

\section{Findings}

As technology moves faster than the enactment of policy and legislation, it is innovation that is now driving new levels of technology acceptance. The bombardment of the diffusion of new innovations, day after day, at an exponential growth rate, has meant that consumers' expectations and their ability to adapt to changes in the marketplace have made them more resilient and to some extent more akin to the trialability of new ideas. But with the onslaught of new inventions, also comes the increasing importance of how these technologies can be used, beyond their original scope of design. It is this aspect, that even in the reports on implants and nanotechnology coming from sober sources of secondary data (figure 6), that the concerns of people vested with the direction of a state's policy, legislation, law enforcement, bio-ethical and health opinions, are similar to those who are generally labeled as "conspiracy theorists" or "religious fundamentalists" or "human rights activists" or "antiglobalisation revolutionaries". The only differentiator in the implantables space, is that the so called "conspiracy theorist" or "religious fundamentalist" will reach for sources of evidence in posing their arguments in completely different domains, than those of the government policymaker or law reform commission or otherwise.

Despite the inspiration for the argument that different groups are putting forward regarding why people should or should not be implanted for commercial applications, it is important to bring diverse groups of people together to debate and discuss what the possibilities might herald, what they might mean today and well into the future. Ignoring the various voices, or dismissing them as outright nonsense, can work to introduce new technologies without the commensurate controls or safeguards in place.
Discussions about human rights, liability and loss, and the potential for an invasion of privacy and breakdown of trust between organizations and citizens or insurmountable control of governments over citizens will have major repercussions well into the future.

We cannot hold to the attitude as possessed by the former IT Manager of the Baja Beach Club in Spain, who when asked repeatedly about the risks replied: "No. Frankly I can only see positive benefits. There are no negatives." However, this kind of thinking does not allow for the critical assessment of the social implications- both intended and unintended consequences- of emerging technologies on society. For example, what might such changes mean for the way people live and work and interact with one another? Are there potential detrimental effects for individuals who bear high tech devices? The current development process is for organizations to patent, then to clinically test if required, and then to deploy. Commercialisation more than ever has become a buzz term- if you can conceive, then you can receive the rewards, presumably some of this in a monetary form. But the successful filing of a patent does not imply that the technology can be deployed without further approval. Consider the patent for a system and method to manufacture a swallowable sensor device of April 2009 [27]. One need only ponder for a moment on what kinds of issues might arise with a sensor device that finds itself in the hands of the wrong kind of doctor.

The risks are present, and words like "consent" and "choice" and "opting-out" have almost become synonymous with politically correct statements. At least for now, we can speak about options and not mere compliance or acknowledgement of reception of identity devices in differing contexts. And if there was anything of magnitude to gain from the case of the Baja Beach Club in Spain, it was that patrons were given an option. The Club did not say, "be chipped or find another club", but who knows how far off this kind of either/or scenario might actually be! We can already see the advent of biometrics in club patronage across Australia. The IT Manager affirmed the importance of consent- "if people want it they can adopt it, if they don't want it, then that's that. The decision must be with the consumer and not with the system creator. We never told anyone at the club- look, now you are under our patronage you must take this technology. No, never. And for the patrons, I must stress again, it was always up to them."

On reflecting on worldwide trials, the IT Manager stated that while the trials were not large scale there were a lot of people looking at the potential. He said: "I always like to see where things are at in this space, and often look for information related to RFID to note the developments. While the vast majority of trials have only had very few people in them, nevertheless they have tested the concept 
works..." As for the IT Manager he hopes for a day in which he does not have to carry cards at all- "when everything is stored on centralized databases, and that my ID will be an implant so I do not have to carry around cumbersome wallets. I would feel very relieved as a consumer if all this would happen. I just want to be free of the extras that are a nuisance." Privacy experts would well warn about the perils of maintaining a false sense of "freedom", "security", and "justice" based around convenience solutions which look like they are making life easier but instead encroaching on our human rights.

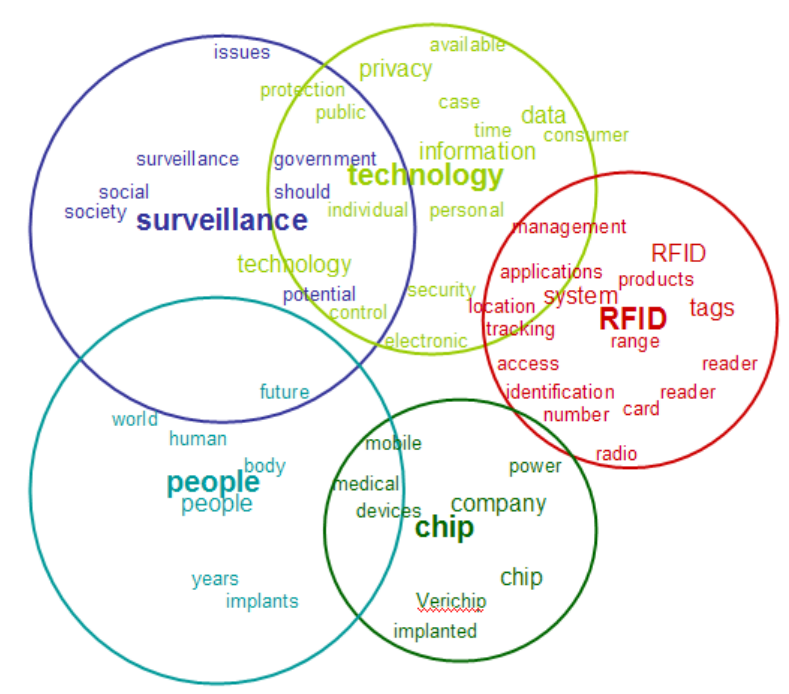

Figure 6 Secondary Online Data Content Analysis which pertains to policy and legal documents and regulations, trade magazines, media

\section{Conclusion}

For now at least, it is the attribute gap, the discrepancy between a potential user's perception of an item of knowledge and how the potential user prefers to perceive that attribute that is the problem in the rate of adoption of human implantable technologies for epayment and access control applications. This exploratory research aimed to present a single case study of the Baja Beach Club in Spain, supported by a single interview with the IT Manager of the club who implemented the implantable solution, and also secondary online data used to support evidence presented. The paper hopes to have conveyed the need to conduct pre-tests with all implantable solutions that are being patented so that the value of the technologies can be enhanced and so that adequate safeguards can be introduced in a timely manner. Another contribution of the paper was in raising awareness of the commercial applications that are sporadically becoming available through the use of information and communication technology (ICT) humancentric implantables.

\section{Acknowledgements}

The authors would like to extend their appreciation to the former IT Manager of the Baja Beach Club, $\mathrm{Mr}$ Serafin Vilaplana for the opportunity to conduct a full length interview, and to Ms Sara Kepa from Indiana University who meticulously translated the original interview transcript.

\section{References}

[1] K. Maney. (12 May 2004) Get chipped, then charge without plastic — you are the card, USA Today.com I Money. [Online]. Available: http://www.usatoday.com/money/industries/technology/m aney/2004-05-12-chip_x.htm

[2] (2004) Baja Beach Club, Spain. [Online]. Available: http://www.bajabeach.es/

[3] (1 October 2004) Baja Beach Club, Netherlands. [Online]. Available: http://www.baja.nl/

[4] L. S. Spatz. (25 December 2004) About the Founder, [Online]. Available: http://www.childrenofheroes.org/aboutthefounder.htm

[5] (2009) About Us, VeriChip. [Online]. Available: http://www.verichipcorp.com/about_us.html

[6] (2009) Safeguarding the World, Digital Angel: About Us. [Online]. Available: http://www.digitalangel.com/about.aspx

[7] FDA. (8 November 2002) Inspections, Compliance, Enforcement, and Criminal Investigations Warning Letter: to Mr. Richard J. Sullivan, Chief Executive Officer, Applied Digital Solutions, Inc, Food and Drug Administration. [Online]. Available: http://www.fda.gov/ICECI/EnforcementActions/Warning Letters/2002/ucm145298.htm

[8] E. Mejia and S. Casey. (24 October 2002) Passive integrated transponder tag with unitary antenna core, US Patent and Trademark Office. [Online]. Available: http://appft.uspto.gov/netacgi/nph-

Parser?Sect $1=$ PTO $2 \&$ Sect $2=$ HITOFF $\& u=\% 2$ Fnetahtml $\%$ 2FPTO\%2Fsearch- 
adv.html\&r=8\&p=1\&f=G\&l=50\&d=PG01\&S1=6400338 $\& \mathrm{OS}=6400338 \& \mathrm{RS}=6400338$

[9] FDA. (12 October 2004) Medical Devices; General Hospital and Personal Use Devices; Classification of Implantable Radiofrequency Transponder System for Patient Identification and Health Information, Food and Drug Administration. [Online]. Available: http://www.fda.gov/OHRMS/DOCKETS/98fr/0427077.htm

[10] G. Gantt. (10 December 2004) Implantable Radiofrequency Transponder System for Patient Identification and Health Information, Guidance for Industry and FDA Staff Class II Special Controls Guidance Document. [Online]. Available: http://www.fda.gov/downloads/MedicalDevices/DeviceRe gulationandGuidance/GuidanceDocuments/ucm072191.pd f

[11] (27 July 2007) VeriChip Corporation VeriMed Patient Identificator VeriChip Implant, FDA: MAUDE Adverse Event Report. [Online]. Available: http://www.accessdata.fda.gov/scripts/cdrh/cfdocs/cfMAU DE/Detail.CFM?MDRFOI_ID=962453

[12] J. Cagan and C. M. Vogel, Creating Breakthrough Products: Innovation from Product Planning to Program Approval. New Jersey: Prentice Hall, 2002.

[13] E. M. Rogers, Diffusion of Innovations, Fourth ed. New York: The Free Press, 1995.

[14] J. Tidd, J. Bessant, and K. Pavitt, Managing Innovation: Integrating Technological, Market and Organisational Change, Second ed. Brisbane: John Wiley and Sons, 2001.

[15] K. Michael and M. G. Michael, Innovative Automatic Identification and Location-Based Services: from Bar Codes to Chip Implants. Hershey: IGI Reference, 2009.

[16] B. von Stamm, Managing Innovation, Design and Creativity. London: John Wiley, 2003.

[17] W. G. Zikmund, Business Research Methods, 7th ed. Australia: Thomson, 2003.
[18] P. D. Leedy and J. E. Ormrod, Practical Research: Planning and Design, 8th ed: Pearson, 2005.

[19] M. Saunders, P. Lewis, and A. Thornhill, Research Methods for Business Students, 4th ed: Prentice Hall, 2007.

[20] (2004) Baja Source, Harper's Index. [Online]. Available: http://harpers.org/index/2004/8/34

[21] J. Tidd and J. Bessant, Managing Innovation: Integrating Technological, Market and Organisational Change, 4th ed. Sussex: John Wiley and Sons, 2009.

[22] D. Leonard-Barton and D. K. Sinha, "Developer-user interaction and user satisfaction in internal technology transfer," Academy of Management Journal, vol. 36, pp. 1125-39, 1993.

[23] J. M. Boyle and D. Novak, "Introduction to Religious and Cultural Perspectives in Bioethics," in The Cambridge Textbook of Bioethics, P. A. Singer and A. M. Viens, Eds.: Cambridge, 2008, pp. 379-81.

[24] (1 November 2006) The glamorous night in the Paseo Marítimo in Barcelona, con SITSMS, [Online]. Available: http://www.sitmobile.com/ingles/noticias.php

[25] S. Rodotà and R. Capurro. (16 March 2005) Ethical Aspects of ICT Implants in the Human Body, Opinion of the European Group on Ethics in Science and New Technologies to the European Commission. [Online]. Available:

http://ec.europa.eu/european_group_ethics/docs/avis20_e n.pdf

[26] K. Albrecht. (2004) Consumers Against Supermarket Privacy Invasion and Numbering, CASPIAN. [Online]. Available: http://www.nocards.org/

[27] M. R. Arneson, W. R. Bandy, R. A. Davenport, K. J. Powell, and M. C. Sloan. (2 April 2009) System and Method for Manufacturing a Swallowable Sensor Device US Patent and Trademark Office. [Online]. Available: http://appft.uspto.gov/netacgi/nph-

Parser?Sect $1=$ PTO $2 \&$ Sect $2=$ HITOFF $\& \mathrm{p}=1 \& \mathrm{u}=\% 2$ Fneta html\%2FPTO\%2Fsearch-

bool.html\&r=1\&f=G\&l=50\&co1=AND\&d=PG01\&s1=20 $090088618 \& \mathrm{OS}=20090088618 \& \mathrm{RS}=20090088618$ 